\title{
Práticas de integração ensino-serviço-comunidade e a formação em Odontologia: possíveis conexões e fluxos no ensino na saúde
}

\author{
Larissa Campos Rodrigues Pinheiro*; Reyjanne Barros de Carvalho**; Patrícia Ferreira de Sousa \\ Viana***
}

* Residência Multiprofissional em Saúde da Família e Comunidade, Universidade Estadual do Piauí

* $\quad$ Mestre em Ciências e Saúde, Universidade Federal do Piauí

*** Mestre em Ciências e Saúde, Docente, Curso de Odontologia, Universidade Federal do Piauí

Recebido em 02/02/2018. Aprovado em 08/12/2018.

\begin{abstract}
RESUMO
A pesquisa objetiva compreender, a partir do ponto de vista do preceptor, as práticas de integração ensino-serviço-comunidade vivenciadas durante a formação em Odontologia. Trata-se de um estudo qualitativo, descritivo e exploratório utilizando a técnica de grupo focal. Emergiram da análise dos dados quatro categorias temáticas: a construção da identidade do preceptor da graduação em Odontologia; a preceptoria e sua polissemia; a Estratégia Saúde da Família como campo de práticas; e potencialidades e fragilidades na integração ensino-serviço-comunidade. Os preceptores reconhecem as contribuições da integração ensino-serviço-comunidade para a formação em Odontologia. O papel do preceptor foi apontado como o de facilitador do aprendizado, que ao exercer sua função também vivencia uma constante atualização teórica. A construção da identidade dos preceptores é percebida como um processo inacabado e são pontuadas estratégias para que sejam concretizadas as mudanças almejadas na formação em Odontologia. A Estratégia Saúde da Família foi percebida como campo de práticas que permite aos discentes perceber na realidade como o sistema funciona. Potencialidades foram citadas na integração dos acadêmicos com a Atenção Primária à Saúde, como o contato com o corpo docente e ocorrência de momentos de formativos. Contudo, são necessários maiores esforços de todo o ambiente acadêmico, e maior implicação da gestão para o estímulo a experiências pedagógicas condizentes com as necessidades em saúde do país. A temática abordada na presente pesquisa abre oportunidade para a realização de outros estudos em diferentes instituições de ensino superior no país que contribuam com a compreensão das contribuições da integração ensino-serviço-comunidade para a formação em Odontologia.
\end{abstract}

Descritores: Odontologia. Preceptoria. Ensino. Aprendizagem. 


\section{INTRODUÇÃO}

A formação em Odontologia foi, historicamente, marcada pelo foco na técnica e na doença, na atuação individual com ênfase na cura e, cada vez mais, clinicamente compartimentalizada. Percebe-se que, apesar das mudanças socioeconômicas e do arcabouço jurídico que rege o modelo assistencial brasileiro, esse contexto ainda está presente, com um padrão de formação profissional que limita o entendimento do contexto macrossocial da saúde, da responsabilidade sobre a saúde das pessoas e das coletividades ${ }^{1,2}$ e do seu papel social na consolidação do Sistema Único de Saúde (SUS).

Na busca por mudanças desse cenário para a formação em Odontologia no Brasil, foram propostas, em 2002, reorganizações das Diretrizes Curriculares Nacionais (DCN) para os cursos de graduação em Odontologia ${ }^{1}$. O objetivo das recomendações é promover a construção de um perfil profissional generalista, humanista, crítico, atuante na prática odontológica em todos os níveis de atenção à saúde; e integral, através de uma articulação entre o ensino, a pesquisa e o sistema de saúde vigente no país ${ }^{3}$. São, assim, norteadas as abordagens contemporâneas de formação que convergem para um perfil acadêmico e profissional com habilidades técnicas e competências condizentes com as realidades epidemiológicas, sociais e políticas do contexto brasileiro ${ }^{4}$.

Comprometida com tais competências, tem ganhado cada vez mais destaque a aproximação entre os espaços de formação, de serviço e o cenário epidemiológico e sanitário presente nos territórios. Representada pela integração ensinoserviço-comunidade, essa aproximação pode ser entendida como uma nova maneira de pensar a formação através do trabalho coordenado e coletivo das instituições de ensino e dos serviços de saúde, buscando ampliar e qualificar a aprendizagem em saúde; a rede de cuidados individuais e coletivos; e a satisfação dos trabalhadores do serviço ${ }^{4-7}$.

Alinhada a essa proposta de mudanças, a Universidade Federal do Piauí (UFPI) propõe, por meio do Projeto Pedagógico do Curso de Bacharelado em Odontologia, a integração dos discentes, com os serviços de saúde e a comunidade por meio de estágios fora do ambiente acadêmico (extramuros), em Unidades Básicas de Saúde (UBS), junto às equipes de Saúde Bucal (eSB) da Estratégia Saúde da Família (ESF) em Teresina, Piauí. Tal proposta curricular busca propiciar ao aluno o contato com diferentes contextos sociais, de vida e de saúde, geral e bucal, além de promover a atuação em saúde coletiva tendo o SUS como cenário real de práticas ${ }^{8}$.

A vivência da prática clínica fora dos muros da instituição formadora permite, na perspectiva de uma aprendizagem de si, dos entornos e dos papéis profissionais, agregar conhecimentos, habilidades e valores ao processo ensino-aprendizagem em saúde. Ressalta-se que a atuação nos serviços públicos de saúde é essencial para as mudanças almejadas no processo de ensino-aprendizagem dos futuros profissionais, na medida em que "para aprender saúde é preciso participar dos espaços onde se faz saúde"4.

O diálogo da academia com os cenários de práticas parece criar um movimento contínuo e recíproco de transferências de recursos cognitivos, científicos e subjetivos. De um lado, é apresentada aos discentes a oportunidade de experienciar condições clínicas, estruturais e relacionais novas, ampliando suas percepções sobre a atuação em sua categoria e multiprofissional, funcionamento da rede de serviços e habilidades subjetivas do cuidado em saúde. Do outro, os profissionais do serviço que, ao atuarem como preceptores, são convidados a estabelecer uma relação ensinanteaprendente à luz de uma formação em saúde em permanente processo de (re)construção. Finalmente, para a comunidade, é vislumbrada a possibilidade de ampliação e melhoria da qualidade 
da atenção em saúde ofertada.

Diante do exposto, a presente pesquisa tem como objetivo compreender, a partir do ponto de vista do preceptor, as práticas de integração ensinoserviço-comunidade vivenciadas durante a formação em odontologia na Universidade Federal do Piauí (UFPI).

\section{METODOLOGIA}

Foi realizada pesquisa qualitativa ${ }^{9}$, descritiva e exploratória, utilizando como dispositivo de produção de dados o grupo focal e, para a análise do conteúdo empírico, a análise de conteúdo descrita por Bardin ${ }^{10}$ (2011). A técnica se baseia na realização de três fases: a pré-análise, com a "leitura flutuante" dos dados obtidos e a escolha dos documentos a serem analisados, a exploração do material, e a escolha de unidades de codificação com sua classificação e categorização e o tratamento dos resultados com a inferência e a interpretação, nas quais os resultados brutos se tornam significativos e válidos ${ }^{10}$.

Para além da produção de dados, após o grupo focal, o estudo oportunizou aos participantes um minicurso de atualização sobre a integração ensino-serviço-comunidade, com a presença de um docente do curso de Odontologia da UFPI. Foram convidados a participar do estudo todos os vinte $\mathrm{e}$ seis cirurgiões-dentistas que atuam nas eSB da ESF em Teresina, os quais, na data da produção de dados da pesquisa, orientavam em serviço os discentes em Odontologia da UFPI. Os preceptores foram convidados pessoalmente em seus locais de trabalho, com o ensejo de que estes se fizessem presentes também no minicurso planejado. O momento de produção de dados foi realizado em um final de semana, em dia que não interferisse nos horários de trabalho dos preceptores, posto que não foi obtida liberação dos mesmos por parte da gestão. Nove preceptores confirmaram presença e cinco compareceram ao grupo focal.

Os profissionais participantes da pesquisa assinaram o Termo de Consentimento Livre e Esclarecido e, para que não fossem identificados, serviram como pseudônimos as palavras que os preceptores utilizaram para sintetizar sua experiência de aproximação ensino-serviçocomunidade: interação, realização pessoal, satisfação, prazer e apoio.

A pesquisa foi aprovada pelo Comitê de Ética em Pesquisa da Universidade Estadual do Piauí sob o parecer de $\mathrm{n}^{\circ}$ 2.132.199, após autorização da Fundação Municipal de Saúde de Teresina.

\section{RESULTADOS E DISCUSSÃO}

Da análise dos dados obtidos durante o grupo focal emergiram quatro categorias temáticas: A construção da identidade do preceptor da graduação em Odontologia; A preceptoria e sua polissemia; A Estratégia Saúde da Família como campo de práticas; e Potencialidades e fragilidades na integração ensino-serviço-comunidade.

\section{A construção da identidade do preceptor da graduação em Odontologia}

A origem do termo preceptor vem do latim praecipio, "mandar com império aos que lhe são inferiores"11. Na literatura médica, em que se observa as primeiras publicações em saúde sobre o tema, são apontadas diferentes funções para o preceptor, nas quais estão incluídas as de orientar, dar apoio, ensinar e compartilhar experiências que ajudem o graduando a se adaptar ao exercício de uma profissão em constante mudança ${ }^{12}$.

A identidade como preceptor foi construída durante a discussão do grupo:

[...] está ali mesmo para dar um suporte para que esse aluno tenha a visão de atuação e possa internalizar aquele momento para que no futuro, quando ele chegar no serviço, já tenha vivido essa experiência [...] é formar um profissional que atue de fato no SUS e atenda às 
necessidades da população. (Preceptor Interação)

A contribuição de um preceptor foi relacionada à sua disponibilidade em dar apoio quando solicitado, cedendo seu local de trabalho como campo de prática para um cirurgião dentista em formação e que pode aplicar ali o que, na teoria, recebe na universidade.

É identificado como um profissional que não integra diretamente o corpo docente da graduação ${ }^{13}$, mas que assume importantes papéis como guiar, estimular o raciocínio e a postura ativa, observar e avaliar o estudante durante as atividades, além de ser capaz de estabelecer um ensino a partir do compartilhamento de suas experiências ${ }^{14}$.

As equipes de saúde bucal, as quais fazem parte os profissionais de saúde pesquisados, se adaptam à presença dos estagiários e realizam modificações em suas agendas de atendimento, para que o dia de receber os discentes perpassasse por todos os grupos de pacientes, incluindo visitas domiciliares e atividades de educação em saúde. Situação semelhante foi percebida por Pereira $e t$ $a l .,{ }^{15}$ (2011) que no cotidiano da prática como preceptor, o profissional de saúde não deixa de realizar seu processo de trabalho rotineiro, e de maneira adicional realiza outras ações para atender e ampliar o projeto de ensino dos discentes.

Os preceptores que recebem os discentes de Odontologia da UFPI atuam por meio da parceria entre o órgão gestor da saúde pública municipal e a universidade. Para o exercício da preceptoria não há incentivo pecuniário. Alguns são egressos e afirmam desempenhar a função de preceptor por reconhecimento aos docentes e à instituição formadora e, principalmente, pelo desejo de proporcionar aos discentes uma formação condizente com as reais necessidades da população:

[...] tento [...] oportunizar situações melhores para eles vivenciarem [...] tento oportunizar com que eles vejam de tudo um pouco, a gente tem um papel assim muito importante, e de grande responsabilidade [...]. (Preceptor Interação)

Outro aspecto é a permanente atualização teórica que o preceptor afirma ter ao vivenciar o contato com os estagiários:

[...] é uma troca [...] é muito boa essa interatividade da gente com eles, quando eles chegam que trazem conhecimentos novos, quando eles colaboram com a gente. (Preceptor Satisfação)

Eu vejo que existem ensinamentos que eles estão recebendo e que eu já estou desatualizada e aprendo com eles também e isso é muito importante, é uma via de mão dupla. (Preceptor Apoio)

Pesquisa com estudantes, professores e preceptores vinculados ao estágio curricular do curso de Odontologia da Universidade Federal do Rio Grande do Sul na APS, evidencia, por meio das narrativas dos preceptores, que a vivência com o estagiário contribuiu para troca de informações e busca de novos conhecimentos. Os estudantes se deparam com novas situações e dúvidas, ao mesmo tempo que trazem consigo a teoria aprendida em sala de aula. Dessa forma, os preceptores são continuamente questionados, o que gera mais interesse do trabalhador em se atualizar e em buscar evidências científicas ${ }^{13}$.

E o que é preciso para construir a identidade do preceptor de Odontologia da UFPI? Identidade pode ser definida como "conjunto de características que distinguem uma pessoa ou uma coisa e por meio das quais é possível individualizá-la"11. Diante do exposto, é possível visualizar que a construção da identidade do preceptor em Odontologia da UFPI ainda é um processo inacabado. São necessários mais momentos teóricos e de discussão sobre o tema, maior inserção dos preceptores nos planejamentos pedagógicos e nos momentos avaliativos dos estágios extramuros, maior engajamento político 
da comunidade acadêmica e implicação da gestão dos serviços de saúde, para que sejam concretizadas as mudanças almejadas na formação em Odontologia.

\section{A preceptoria e sua polissemia}

A preceptoria pode ser reconhecida como uma prática articuladora das abordagens teóricas com o cenário prático do serviço, com foco na formação em saúde. É percebida como um elemento pedagógico fundamental na medida em que apresenta o trabalho como fonte de saberes e experiências ${ }^{7,14}$.

O primeiro sentido emergido sobre a função da preceptoria no processo de integração ensinoserviço-comunidade faz referência a preceptoria como facilitadora do aprendizado, que complementa a formação dada pela academia:

[...] preceptoria a gente entende que é facilitar [...] é encorajar, porque o aluno da universidade [...] sai com medo de fazer tudo. (Preceptor Satisfação pessoal)

Ao adentrarem em uma realidade distinta das clínicas integradas da universidade, os estudantes deparam-se com diferentes contextos sociais, organizacionais e relacionais. A nova experiência oportuniza, além da aplicação dos conhecimentos teóricos obtidos na sala de aula, uma complementação por meio da vivência diante dos determinantes de saúde imbricados no território.

Estudos apontam para a complementariedade das atividades de estágio extramuros na formação acadêmica e menciona que estão relacionadas a avanços na compreensão da interdisciplinaridade, ao oportunizarem a atuação em equipe multiprofissional, do funcionamento da rede de serviços de saúde, através da referência e contra referência, além da possibilidade de problematização e compreensão ampla do processo saúde/doença $^{16,17}$.

O segundo sentido abordado traz a preceptoria como canal para a formação na realidade do serviço público, cenário de prática profissional que grande parte dos estudantes encontram após a graduação:

[...] preceptoria é uma troca de experiências com os estudantes [...] é a gente trazer esse aluno para dentro de uma realidade que ele vai estar lidando depois da faculdade [...] essa realidade da comunidade [...] e procurar realmente formar esse aluno [...] para visão de atuação na ESF. (Preceptor Prazer)

[.... Contribui na tentativa de induzir na cabeça desse aluno que ele não tem uma formação exclusiva de clínica e aquela visão exclusivamente lucrativa, mas que ele tenha uma visão de atendimento humanizado, de acolhimento. (Preceptor Prazer)

$\mathrm{Na}$ atividade de preceptoria, ocorrem trocas entre profissionais, discentes, em que os atores estabelecem seus papéis sociais na confluência de seus saberes, modos de ser e de ver o mundo ${ }^{5}$. São essas trocam que estimulam as ações relacionais pautadas na atuação interdisciplinar, em clínica ampliada e no acolhimento e vínculo com os usuários, com a manutenção da saúde como finalidade última de um trabalho em defesa da vida individual e coletiva ${ }^{18}$.

O terceiro sentido aborda a importância do compartilhamento das fragilidades existentes no serviço público durante a preceptoria, estratégia para que os discentes se percebam integrantes da realidade do território:

[...] o papel da preceptoria é a formação de um profissional voltado para o SUS [...] ver que existem problemas no sistema, de estrutura física, recursos ínfimos relacionados, mas que não destrói isso [...] que há potencialidade. (Preceptor Interação)

[...] a preceptoria, ele ir para UBS é ele ver uma outra realidade [...] ver que mesmo 
que essa realidade funcione tão bem como a ideal, dá para chegar perto do ideal com o que você tem nas mãos [...]. (Preceptor Prazer)

Ao desenvolver suas ações de enfrentamento das fragilidades, os profissionais do serviço não devem se limitar à deliberação de fins, mas buscar meios de elaborar uma decisão sem separar o pensar do fazer. Portanto, é essencial durante o acompanhamento de discentes introduzir o aluno nos problemas que o desafiarão, levando-o a buscar formas de solucioná-los. Estudos demonstram que experiências positivas de preceptoria, junto a um profissional considerado 'competente', resultam em um modelo de trabalhador para os estudantes. Além de atuar como um incentivador de uma prática reflexiva ${ }^{13}$.

Outro sentido reconhece a preceptoria como capaz de ampliar as visões do aluno sobre a atuação do Cirurgião-Dentista no SUS, sobrepondo possíveis imagens de inferioridade e desorganização dos serviços públicos de saúde:

[...] eles ficam muito recompensados, eles gostam [...] chegam muitas vezes para a gente e falam que tinha uma visão e, depois que tiveram a preceptoria, já tem uma outra ideia de como é que funciona. (Preceptor Prazer)

Como base no exposto, pode ser visualizada a multiplicidade de sentidos atreladas à preceptoria que vai desde o apoio ao aprendizado; estratégia para a formação profissional com base na realidade do território; canal para a visualização e enfrentamento de barreiras; e mecanismo de ampliação da visão sobre a atuação na ESF. Assim, pode ser percebida a complexidade dessa proposta pedagógica por meio da qual são desenhadas mudanças nos cenários de formação em saúde.

\section{A Estratégia Saúde da Família como campo de} práticas

As disciplinas do estágio supervisionado extramuros do curso de Odontologia da UFPI propõem a vivência dos estudantes no SUS voltados à atuação do CD na ESF. A abordagem territorial da estratégia concebe a reflexão sobre o cotidiano real das pessoas e os determinantes da saúde existentes. O cuidado de famílias e indivíduos inseridos em uma realidade dinâmica traz novos significados às ações de saúde e permite um aprendizado vivo e transformador ${ }^{14}$ :

[...] quando eles vêm para as UBS e eles tem um contato direto com essa população [...], e eles veem na realidade como o sistema funciona. (Preceptor Prazer)

Ressalta-se que a experiência de estágio na qual o aluno se adequa a dinâmica de funcionamento de uma eSB é decisiva para a inserção dos estudantes de Odontologia no mercado de trabalho, pois simula a realidade que grande parte dos futuros profissionais encontrará após a conclusão do curso ${ }^{19,20}$. Essa diversificação dos cenários de aprendizagem permite a transformação da prática dos estudantes, que passam a atuar sobre problemas reais, assumir responsabilidades crescentes e refletir sobre seus papéis profissionais e sociais ${ }^{7,21}$ :

[...] então, eles veem uma realidade acho que é uma visão que nem sempre ele vê na universidade e lá eles têm a oportunidade de ver coisas diferentes. (Preceptor Satisfação)

Lá na nossa unidade, alguns são questionadores, outros fazem o que a gente diz para fazer [...] a gente vai dando as outras opções para eles para aquele problema e eles começam a ter uma outra visão, é uma outra forma que eu acho que na faculdade eles não veem. (Preceptor Prazer)

A atuação na ESF, com a vinculação de indivíduos e famílias em territórios adscritos oportuniza, ainda, um contato mais estreito com a realidade local de uma população ${ }^{13}$, com estímulo 
à percepção dos estudantes sobre o processo saúde-doença no território, engajamento social, humanização e longitudinalidade do cuidado.

Os estágios extramuros são percebidos como locais de aperfeiçoamento para a formação dos discentes, tendo como foco principal a qualidade dos serviços prestados aos usuários:

[A ESF] não é um campo de experiências onde eles vão tentar fazer o que não tem coragem de fazer na universidade [...] fazer o que eles já sabem fazer e ganhar agilidade, velocidade de trabalho $e$ segurança para fazer sem os olhares do professor. (Preceptor Realização pessoal)

[...] no setor público [ESF], tudo é muito difícil, mas tudo é muito mais bonito também, porque quando você consegue vencer essas dificuldades o seu grau de satisfação é muito superior, você pode ter certeza que a sua certeza de dever cumprido é espetacular. (Preceptor Realização pessoal)

A integração ensino-serviço comunidade gera um movimento em que todos se beneficiam. A contrapartida da aprendizagem dos estudantes para o serviço acontece através do estímulo à reorientação de práticas de cuidado, que potencializa as ações na estratégia saúde da família, e agrega novas informações teóricas para a atenção em saúde ${ }^{7,14,22}$.

Dessa forma, os estágios nos serviços de saúde precisam ser olhados pelos gestores e profissionais da saúde como espaços concretos em que as mudanças podem acontecer mutuamente, ressignificando as suas práticas ${ }^{5,23}$.

São nesses espaços que a construção de conhecimento se difunde por todos os sujeitos que por ali passam ${ }^{5}$ e ocorre no cotidiano, nas relações entre sujeitos, e na comunicaçãointeração de seus projetos $^{24}$ com foco em uma assistência em saúde integral, humana e resolutiva.

\section{Potencialidades e fragilidades na integração ensino-serviço-comunidade}

A integração ensino-serviço-comunidade constitui um dos pilares fundamentais nos processos de mudança do ensino e estratégia primordial na consolidação do $\mathrm{SUS}^{5,7}$. São os diálogos entre o trabalho e o ensino na saúde que permitem a criação de um lócus privilegiado para a percepção do aluno acerca do outro no cotidiano do cuidado. O diálogo com os docentes da UFPI é reconhecido como uma potencialidade essencial na transformação do ensino em Odontologia:

Eu acho importante esse contato também para gente colocar as nossas experiências do semestre anterior e o que pode ser melhorado para o próximo semestre. (Preceptor Interação)

É importante também porque a gente sabe que as políticas mudam muito rápido, então, é importante saber como que vai ser, qual forma vai ser dada para a formação $e$ se vai continuar sendo da forma que vem sendo feita. (Preceptor Interação)

Destaca-se a importância da aproximação entre os cenários da universidade e os de prática extramuros, como um 'casamento de saberes próprios', no qual as decisões são tomadas por meio de diálogos e pactos entre preceptor-docentediscente $^{14,22}$. Os pactos devem ser considerados na medida em que na integração entre ensino e trabalho há vários atores envolvidos, os quais possuem realidades de vida e filosofias de formação distintas, incluindo a própria concepção de saúde de cada um ${ }^{18}$.

O diálogo entre docentes e preceptores é um requisito importante para a efetivação das atividades de integração ensino-serviçocomunidade: 
De certa forma, esse contato com os professores eles sabem que está acontecendo com os estudantes na unidade e a gente sabe o que eles estão vendo dentro da faculdade, ou seja, é uma troca, eles tão na faculdade e a gente vai e na preceptoria fala outra. Tendo esse contato preceptor-professor tem como uniformizar uma informação para eles. (Preceptor Prazer)

São realizadas reuniões dos preceptores com os docentes das disciplinas de estágio extramuros em que são oportunizadas discussões sobre a atividade da preceptoria e temas clínicos. Apesar desses momentos já realizados, é sugerido que estes possam ser mais frequentes e com participação mais ativa nos planejamentos das atividades dos estágios.

Albuquerque et al., ${ }^{5}$ (2008) apontam a importância da participação dos profissionais dos serviços nas discussões pedagógicas de formação na área da saúde. Assim como em momentos de avaliação e acompanhamento, nos quais devem ser oportunizados espaços de diálogo em que docentes e preceptores possam exerçam seus papéis de protagonistas na formação ${ }^{14}$. O conhecimento das Diretrizes Curriculares, dos objetivos do curso e do perfil do egresso também precisam ser discutidos com os profissionais, para que estes possam compreender o seu papel na formação do estudante ${ }^{20}$.

É também nos lócus da integração ensinoserviço-comunidade que se explicitam conflitos, e barreiras, sejam relacionados a fatores estruturais ${ }^{20}$, e/ou relacionais nos espaços de cuidados, sejam por entraves vindos do planejamento acadêmico:

Eu vejo uma barreira que vem de dentro da universidade, deveria haver uma integração maior entre as disciplinas, porque todas, sem exceção, as duplas que eu recebo se queixam que o professor da aula da manhã toma muito tempo ao ponto de extrapolar, e dificultar o translado deles pra chegar ao meu posto. Tem que haver uma conversa, vamos interagir, todos têm que fazer com que as coisas funcionem. (Preceptor Realização pessoal)

O trabalho de Viana et al., ${ }^{25}$ (2015) com estudantes do curso de Odontologia da Universidade Federal do Piauí, apresenta a percepção dos estudantes acerca das atividades extramurais realizadas, as quais apontam barreiras como o alheamento dos docentes responsáveis pelas disciplinas clínicas em relação às atividades em saúde coletiva e que dificulta a consolidação da integração ensino-serviço-comunidade no curso.

As percepções críticas dos estudantes revelam uma realidade na qual uma hierarquia pode ser percebida pelos estudantes dentro da academia: as disciplinas ditas clínicas com maior importância em relação às disciplinas e estágios voltados à saúde coletiva, com uma visível separação entre a formação para o SUS e a formação para o mercado privado ${ }^{25}$.

Apesar de todas as possibilidades existentes nos espaços de integração ensino-serviço, é fato perceber que não se podem gerar mudanças na formação em saúde sem que haja uma conexão interdisciplinar. É necessário que todo o ambiente acadêmico convirja para a formação de profissionais que respondam adequadamente às necessidades do sistema de saúde do país ${ }^{19}$, reconhecendo a relevância social do papel da universidade.

Barreiras estruturais como espaço físico reduzido e precárias condições de infraestrutura das unidades de saúde são identificadas como dificuldades para as práticas de estágio ${ }^{20}$ Os preceptores percebem a importância de vivenciar estas dificuldades juntamente com os discentes para contextualização deles na realidade do serviço:

[...] a barreira eu acho que é esse conformar, uma situação que o aluno vai 
pra UBS vê o que que tem de defeito. A gente precisa parar um pouquinho essa postura de buscar só o que tem de defeito. $Q$ que a gente poderia tirar dali como aprendizado para trabalhar futuramente esses profissionais que lá na frente pode ser um gestor? Nós temos uma grande responsabilidade nisso como preceptor de estar mostrando para ele como contornar essas dificuldades e tentar potencializar cada vez mais esse sistema para existir a resolutividade das nossas ações. (Preceptor Interação)

A possibilidade de vivenciar a realidade dos serviços de saúde não deve estimular julgamentos negativos ao modo de funcionamento dos serviços. Deve ser proposta uma aprendizagem reflexiva e que perpasse pela organização dos processos de trabalho, com foco na formação de um profissional transformador de uma realidade ${ }^{5,19}$.

Outra barreira que não foi falada pelos preceptores, pôde ser percebida durante o desenvolvimento da pesquisa. A proposta do estudo, para além da compreensão da integração ensino-serviço-comunidade foi proporcionar um momento pedagógico aos profissionais da APS. Contudo, a "pesquisa-formação" não foi reconhecida pela gestão e os preceptores não obtiveram liberação para sua participação, fazendo com que o estudo fosse realizado em um final de semana.

A baixa adesão dos preceptores pode ser assim justificada? De fato, não é algo que se possa inferir. Todavia, tal situação demonstra que as fragilidades do componente "serviço" não existem apenas no território, mas também estão presentes na gestão. $\mathrm{O}$ não comprometimento com a integração ensino-serviço-comunidade pressupõe também o não comprometimento com a consolidação da reforma política em saúde do Brasil.

A Odontologia da UFPI considera importante e oportuniza diálogos entre a academia e os cenários de prática, ainda que seja necessários maiores esforços do ambiente acadêmico em favor da consolidação do projeto pedagógico do curso. Barreiras estruturais e de gestão demonstram fragilidades ainda existentes no cenário aqui discutido. Contudo, a compreensão das práticas de integração ensino-serviço-comunidade no curso de Odontologia da UFPI propõe implicações que contribuem para a implementação das mudanças desejadas à formação em odontologia no Brasil.

\section{CONSIDERAÇÕES FINAIS}

Os preceptores reconhecem as contribuições da integração ensino-serviço-comunidade para a formação em Odontologia. O papel do preceptor foi apontado como o de um facilitador do aprendizado, que ao exercer sua função também vivencia uma constante atualização teórica. A construção da identidade dos preceptores da UFPI é percebida como um processo inacabado e são pontuadas estratégias para que sejam concretizadas as mudanças almejadas na formação em Odontologia.

A ESF foi percebida como campo de práticas que permite aos discentes perceber na realidade como o sistema funciona. Potencialidades foram citadas na integração dos acadêmicos com a APS em Teresina, como o contato com o corpo docente das disciplinas de estágio. Contudo, são necessários maiores esforços de todo o ambiente acadêmico, e maior implicação da gestão para o estímulo a experiências pedagógicas significativas e condizentes com as necessidades em saúde do país.

A temática abordada na presente pesquisa abre oportunidade para a realização de outros estudos em diferentes Instituições de Ensino Superior no país que contribuam com a compreensão das contribuições da integração ensino-serviço-comunidade para a formação em Odontologia. 


\section{AGRADECIMENTOS}

Aos preceptores que cordialmente manifestaram interesse e participaram da pesquisa.

\section{ABSTRACT}

Practices of teaching-service-community integration and training in Dentistry: possible connections and flows in health education

The research aims to understand, from the point of view of the preceptor, the practices of integration teaching-service-community experienced during the training in the Dentistry program. It is a qualitative, descriptive and exploratory study using the focal group technique. From the analysis of the data emerged four thematic categories: the construction of the identity of the preceptor of the Dentistry program; the preceptorship and its polysemy; the Family Health Strategy as a field of practice; and potentialities and weaknesses in teaching-service-community integration. The preceptors acknowledge the contributions of the teaching-service-community integration for the training in the Dentistry program. The role of the preceptor was pointed out as the facilitator of learning, who in exercising his function also experiences a constant theoretical update. The construction of the identity of the preceptors is realized as an unfinished process and strategies are pointed out so that the desired changes in the formation in Dentistry can be realized. The Family Health Strategy was realized as a field of practices that allows students to realize in reality how the system works. Potentialities were cited in the integration of the academics with Primary Health Care, such as the contact with the teaching staff and the occurrence of formative moments. However, greater efforts are needed throughout the academic environment, and greater involvement of management in stimulating pedagogical experiences consistent with the health needs of the country. The theme addressed in the present research opens the possibility for other studies in different institutions of higher education in the country that contribute to the understanding of the contributions of the teaching-service-community integration for the training in Dentistry.

Descriptors: Dentistry. Preceptorship.

Teaching. Learning.

\section{REFERÊNCIAS}

1. Grande I, Prochnow R, Saab R, Pizzatto E. Desafios na formação do Cirurgião-Dentista para o SUS. Rev ABENO. 2016;16(2):2-6.

2. Weber C, Fagundes ML, Tambara A, Dirlan E, Beltrame A, Krassman A, et al. Integração ensino-serviço-gestão na saúde bucal em Santa Maria e região: relato de experiência em estágio curricular acadêmico e Residência Multiprofissional. Rev ABENO. 2018:17 (4):144-52.

3. Associação Brasileira de Ensino Odontológico (ABENO). Diretrizes da ABENO para a definição do estágio supervisionado nos cursos de Odontologia. Rev ABENO. 2002; 2(1):13-8.

4. Faé JM, Silva JMF, Carvalho RB, Esposti CDD, Pacheco KTS. A integração ensinoserviço em Odontologia no Brasil. Rev ABENO. 2016;16(3):7-18.

5. Albuquerque VS, Gomes AP, Rezende CHA, Sampaio MX, Dias OV Lugarinho RM. A integração ensino-serviço no contexto dos processos de mudança na formação superior dos profissionais da saúde. Rev Bras Educ Méd. 2008;32(3) :356-62.

6. Albarado AJ, Rodrigues, MAF, Cavadinha ET. A comunicação na parceria ensinoserviço-comunidade. Tempus. 2016;9(1) :25-42.

7. Finkler $\mathrm{M}$, Caetano JC, Ramos RFS. Integração "ensino-serviço" no processo de mudança na formação profisisonal em Odontologia. Interface (Botucatu). 2011; 
15(39):1053-70.

8. Universidade Federal do Piauí. Alterações do projeto pedagógico do curso de graduação, bacharelado em Odontologia. Teresina: Universidade Federal do Piauí, 2012.

9. Minayo MCS (Org.). Pesquisa Social: Teoria, método e criatividade. Petrópolis: Vozes; 2016.20p.

10. Bardin L. Análise de conteúdo. São Paulo: Edições 70; 2011.

11. Houaiss A, Villar MS. Dicionário Houaiss da Língua Portuguesa. Rio de Janeiro: Objetiva; 2001.

12. Botti SHO, Rego S. Preceptor, supervisor, tutor e mentor: quais são seus papéis? Rev Bras Educ Méd. 2008;32(3):363- 73.

13. da Luz GW, Toassi RFC. Percepções sobre o preceptor cirurgião-dentista da Atenção Primária à Saúde no ensino da Odontologia. Rev ABENO. 2016;16(1):212.

14. Forte FDS, Fernandes Pessoa TRR, Morais Freitas CHS, Pereira CAL, Carvalho Junior PM. Reorientação na formação de cirurgiões-dentistas: o olhar dos preceptores sobre estágios supervisionados no Sistema Único de Saúde (SUS). Interface Comun Saúde Educ. 2015;19(Supl 1):831-43.

15. Pereira JG, Fracolli LA. Articulação ensinoserviço e vigilância da saúde: a percepção de trabalhadores de saúde de um distrito escola. Trab Educ Saúde. 2011;9(1):63-75.

16. Bonin JE, Oliveira JGS, Nascimento JM, Rezende ME, Stopato SP, Leite ICG. Liga acadêmica de medicina de família e comunidade: instrumento de complementação curricular. Rev APS. 2011; 14:50-7.

17. Mestriner Júnior W, Mestriner SF, Bulgarelli AF, Mishima SM. O desenvolvimento de competências em atenção básica à saúde: a experiência no projeto Huka-Katu. Ciênc Saúde Coletiva. 2011; 16(supl):903-12.

18. Franco TB, Merhy EE. Programa de Saúde da Família (PSF): Contradições de um programa destinado à mudança do modelo tecnoassistencial In: Merhy EE, Magalhães Júnior HM, Rimoli J, Franco TB, Bueno WS. O trabalho em saúde: olhando e experienciando o SUS no cotidiano. 3.ed. São Paulo: Hucitec; 2006. p. 53-124.

19. Toassi RFC, Davoglio RS, Lemos VMA. Integração ensino-serviço-comunidade: o estágio na atenção básica da graduação em Odontologia. Educ Rev. 2012; 28(4):22342.

20. Trajman A, Assunção N, Venturi M, Tobias D, Toschi W, Brant V. A preceptoria na rede básica da Secretaria Municipal de Saúde do Rio de Janeiro: opinião dos profissionais de Saúde. Rev Bras Educ Méd.2009;33(1):2432.

21. Souza AL, Carcereri DL. Estudo qualitativo da integração ensino-serviço em um curso de graduação em Odontologia. Interface (Botucatu). 2011; 15(3):1071-84.

22. Vendruscolo C, Ferraz F, Prado ML, Kleba ME, Reibnitz KS. Integração ensino-serviço e sua interface no contexto da reorientação da formação na saúde. Interface Comunic Saúde Educ. 2016; 20:1015-25.

23. Vasconcelos ACF, Stedefeldt E, Frutuoso MFP. Uma experiência de integração ensino-serviço e a mudança de práticas profissionais: com a palavra, os profissionais de saúde. Interface Comunic Saúde Educ. 2016; 20(56):147-58.

24. Dias HS, Lima LD, Teixeira M. A trajetória da política nacional de reorientação da formação profissional em saúde no SUS. Ciênc Saúde Coletiva. 2013; 18(6):1613-24. 25. Viana PFS, Adad SJHC, Pedrosa JIS. 
Reverberações das experiências extramurais no ensino da Odontologia. ABCS Health Sciences. 2015;40(3).

\section{Correspondência para:}

Larissa Campos Rodrigues Pinheiro.

e-mail: larissacamposrpinheiro@gmail.com Universidade Estadual do Piauí - Centro de Ciências da Saúde Coordenação da Residência Multiprofissional em Saúde da Família e Comunidade Rua Olavo Bilac, 2335 Centro (Sul) 64001-280 Teresina/PI 